\title{
Papel da Documentação na Implantação de uma Nova Politica de Pessoal
}

\section{Vera da Silva Medeiros}

\section{$\mathrm{O}$}

TEMÁrio da $1^{\text {a }}$ Reunião de Diretores e Chefes de Pessoal do Serviço Público Civil dá União reservou para o Serviço de Documentação do DASP o «Papel da Documentação na Implantação da Nova Politica de Pessoal», assunto que abrange a Análise do Boletim Informativo «DiRETRIZES». A abordagem dêste problema parece-me, antes de mais nada, uma tarefa de especialistas, uma vez que a Documentação, como tôda atividade humana, já se tornou uma especialidade. Não me refiro aqui à velha definição do especialista como o cidadão «que sabe cada vez mais. de cada vez menos coisas», mas sim como aquêle que conhece, em profundidade, determinado assunto; aquêle que estudou tôdas as. implicações de certa matéria; enfim, a que os americanos chamam de «Expert». Por isso, peço que me relevem o uso de alguns conceitos que tomei emprestados aos especialistas da Documentação. Procurarei, tanto quanto possivel, não abusar do jargão típico que é a linguagem com que os especialistas de qualquer matéria procuram simplificar certas noções ou imagens indispensáveis à compreensão de suas idéias, o que, por sinal, já é matéria de outra especialidade: a Comunicação.

Vou-me permitir uma outra advertência prévia, que me parece tão essencial quanto a anterior. Não pretendo traduzir ou formular conceitos teóricos ou metodológicos sôbre a matéria, mesmo por que sei que neste auditório há expressões intelectuais muito mais autorizadas do que eu para fazê-lo. Cingir-me-ei, portanto, a alguns aspectos práticos e objetivos que justificam a minha presença neste encontro e que, em última análise, dizem respeito e aguardam relação com o nosso trabalho. Vejamos alguns"dos que mais nos interessam.

O relatório final da Comissão de Reforma do Ministério da Fazenda, divulgado em 1967, revela que:

Um levantamento feito pelo setor de legislação da Comissão de Reforma trouxe à tona a seguinte fato: em fevereiro de 1966, havia em vigor, no Govêrno Federal, nada menos de 205 leis, 316 decretos-leis e 467 decretos que continham dispositivos referentes a pessoal. 
somados, são 988 documentos legais com os quais estão, direta ou indiretamente relacionados, os órgãos de pesscal do Serviço Público Civil da União. Se acrescentarmos a êsse número os diplomas legais referentes a pessoal expedidos de fevereiro de 1966 até hoje não será exagêro afirmar que a matéria-prima básica com que têm que lidar os encarregados da administração do pessoal atinge a mais de um milhar de textos. A problemática que envolve a Legislação do Pessoal, entretanto, näo se esgota nos textos legais, isto é, nas Leis, Decretos e Regulamentos. Ao contrário, vai mais além. Abrange, também, pareceres, que têm fôrça normativa, despachos, decisões e circulares que fazem da exegese administrativa um verdadeiro exercícia de paciência e labor intelectual que, permitam-me a expressão, é tìpicamente chinês...

Ora, a interpretação legal é, inegàvelmente, uma especialidade no campo do Direito. E foi em função dessa exigência que se deu início à codificação, primeiro das Leis, depois da jurisprudência, até atingir as consultas, os éditos dos magistrados e as respostas dos jurisconsultos. E isso, numa época em que o número de Leis do Universo Jurídico não atingia, sequer, a uma centena. O que dizer, então, de um conjunto de normas que deve abranger cêrca de dois milhares de textos? E textos que se conjugam, que se harmonizam, que se entrelaçam com outros que só remotamente referem-se ao problema do pessoal, quando não se contradizem ou se conflitam?

As soluções até há pouco encontradas para enfrentar êsse desafio não passavam de tentativas, até certo ponto empíricas. Elas vão dos ementários mais ou menos periódicos editados pelas bibliotecas até à célebre coleção de recortes de leis, decretos e decisões administrativas que, em última análise, constitui o VADEMÉcum dos administradores de pessoal. Se êsses instrumentos servem de orientação geral, nos problemas mais corriqueiros e usuais do serviço público, não atendem, entretanto, ao exame casuístico que interessa particularmente a cada funcionário. Mesmo por que é mais ou menos óbvio que, em matéria de pessoal, aplicase o velho refrão de que «cada casa é um nôvo caso».

As chamadas «Leis de Clientela», as Leis de exceção ou de grupos, normalmente de vigência periódica no tempo e no espaço constituiam, em 'geral, um elemento que servia para tumultuar, ainda mais, o já complexo e extenso processo administrativo do pessoal na administração pública. Daí por que a aplicação de certas normas e prescrições, tais como as que criaram os institutos do «ENQUADRAMENTO» e, particularmente, o da «READAPTAÇÃO», transformavam $\sim$ se, pouco a pouco, numa rotina sem fim, pràticamente ilimitada. A conseqüência fatal dêsse acúmulo de problemas foi, lògicamente, aquela a que nos habituamos na convivência de nosso trabalho diário: processos, consultas, pareceres, decisões, despachas, ações, jurisprudência administrativa e judiciária no meio da qual se debate, inexoràvelmente e sem socorro, o administrador do pessoal. Premido pelas contingências de tôda série de reivin- 
dicações de um lado, e cerceado pelo emaranhado de leis entre as quais tem que se mover cautelosamente, a encarregado do pessoal no serviço público é como uma espécie de prático que não conhece a barra, mas tem que levar o navio ao pôrto. Sua tarefa prática consiste, assim, em navegar, cautelosamente, entre recifes, utilizanda-se do método da tentativa. Nesse mister, êle se vê obrigado, muitas vêzes, para legitimar situações de fato, a infringir um dispositivo aqui, outro adiante; erra às vêzes por omissão, outras vêzes por desconhecimento; faz do exemplo e da sugestão, quando não do palpite ou da analogia, a sua bússola.

Êste ainda é, em alguns casos, o retrato fiel, o quadro real, ainda que sombrio, da administração do pessoal em muitos órgãos. Mais do que isso, no entanto, é o resultado do empirismo, da falta de método e de sistematização, problemas contra os quais lutou o DASP, desde início, e que constitui mesmo a sua razão de ser.

Não é sem propósito afirmar que a racionalização, a implantação de uma sistemática, e mais do que uma sistemática, de uma filosofia administrativa, é o próprio objetivo dêste Departamento. Tanto que as mais persistentes resistências à mudança, identificadas em toda processo de transformação social, manifestaram-se sempre contra êste órgão. É forçoso reconhecer, entretanto, que os resultados obtidos nem sempre podiam ser proporcionais à soma dos esforços empregados; mesmo porque, embora possamos contribuir para as soluções, estas nem sempre dependem de nós, entidade normativa e orientadora que somos. Muitas vêzes, no afã de superar as dificuldades e os antagonismos gerados por tôda política de pessoal, talvez tenhamos nos esquecido que a base de tôda organização reside, como assinalou um ilustre ex-Diretor do DASP, no «material humano, de cuja qualidade e motivação depende o destino das emprêsas». Daí por que, acrescenta êle, «o pessoal tanto pode servir como ponto de estrangulamento, como, ao contrário, de elemento de progresso».

Não posso afirmar, mas posso aventar a hipótese de que esta possa ser uma das razões por que tantas reformas, antes tentadas, jamais se objetivaram. Penso que teriam obtido melhor êxito, se tivessem levado em conta a natureza humana, sempre muito ciosa de suas próprias prerrogativas e privilégios.

Foi sopesando essa realidade, foi com o objetivo de superar os pontos de estrangulamento, transformando-os em pólos de progresso, que a Diretriz Básica de Reforma Administrativa, consubs tanciada no Decreto-lei n.200, de 1967, deu tanta ênfase ao problema do pessoal, que é o único elemento decisiva e transcendental de tôda e qualquer transformação. E o fêz, é necessário que se diga, enfrentando o mais desafiador das problemas: o da legislação do pessoal.

Os principios básicos da Reforma Administrativa prevêem, especificamente, a descentralização e a Delegação de Competência, reconhecendo portanto que aquela depende intimamente desta, pela revisão da legislação e das normas regulamentares relativas 
ao pessoal, visando, entre outros objetivos, à «concessão de maior autonomia aos dirigentes e chefes na administração de pessoal», e ao «estabelecimento de mecanismos adequados à apresentação por parte dos servidores, nos vários níveis organizacionais, de suas reclamações e reivindicações, bem como a rápida apreciação, pelos Órgãos Administrativos competentes, dos assuntos nelas contidos».

A concretização dessas providências, porém, implica numa série de medidas infra-estruturais, uma das quais - por sinal de maior urgência - é o preparo de especialistas que possam assegurar uma atividade normativa de caráter padronizado, nos esquemas de atendimento e solução dos problemas de pessoal. Essa orientação uniforme tem, forçosamente, que ser traduzida em critérios padronizados para que decisões discrepantes não criem precedentes e exceções que podem ser fatais à politica de pessoal.

Devemos considerar que, só à medida em que os canais superiores da administração forem sendo desobstruidos dos problemas casuísticos que entravam e emperram o poder de decisão dos seus dirigentes, poderão êles se dedicar, com a urgência e a velocidade que o progresso exige de uma administração dinâmica, às grandes tarefas que devem constituir objeto de suas preocupações.

Para preparar êste grande passo que é a Descentralização através da Delegação, é que o DASP está se armando de instrumentos que lhe permitirão vencer o grande empecilho da complexidade da legislação administrativa do pessaal.

É de reconhecer-se que o preparo de especialistas no campo da Administração de Pessoal pressupõe uma longa e custosa formação que não se esgota ao fim de um período. E isso exatamente porque a legislação não é um conjunto de conhecimentos estatísticos que, dominados ao fim de algum tempo, esgotam a matéria.

Muito ao contrário, como as leis resultam de um conjunto de circunstâncias mutáveis, e visam atender sobretudo às necessidades do corpo social, elas são essencialmente dinâmicas. Requerem, acima de tudo, um ajustamento contínuo, uma atualização perma nente. Esste mesma problema, aliás, enfrentam os especialistas em todos os campos do conhecimento científico, onde as verdades não são senão provisòriamente estabelecidas. Temos, portanto, que nos valer dos mesmos meios, dos mesmos processos e das mesmas soluções utilizadas pelos cientistas.

Comentando o problema da variedade bibliográfica e da quantidade de informação científica de que têm que se valer os intelec tuais e os cientistas de hoje, Ortega y Gasset concluía melancólico sua intervenção num congresso Internacional de Bibliotecários, afirmando: «A cultura que havia libertado o homem da selva primária, arroja - de nôvo em uma selva de livros não menos inextrincável e avassaladora». Guardadas as proporções, é êsse exatamente o problema com que se defronta, atualmente, o especialista da administração do pessoal; e convém lembrar que êsse emaranhado de leis e textos legais, só tende a aumentar com o passar do 
tempo, como fruto das próprias exigências do progresso e como resultado do próprio crescimento administrativo que é, em última análise, consequiência do desenvolvimento do país. Felizmente para nós, o nosso problema se reduz a uma só especialidade...

A necessidade de colocar a informação adequada ao alcance dos que dela devem se utilizar foi exatamente que conferiu autonomia à Documentação. Sei que não é necessário deter $-m e$ numa análise dos problemas relacionados com a Documentação, tendo em vista a natureza e as condições culturais dêste auditório. Per mito-me, apenas, lembrar que alguns dos mais sérios problemas no âmbito científico foram ou estão sendo adequadamente resolvidos com o auxilio das técnicas de Documentação que, em alguns setores, não dispensa as formas mais sofisticadas da memória eletrônica, dada a complexidade dos assuntos cuja divulgação se requer.

A Comissão de energia Atômica do Estados Unidos, por exemplo, distribui cêrca de seis milhões de exemplares de Relatórios anualmente. As perspectivas de progresso abertas com a pesquisa de energia nuclear em todo o mundo são de tal ordem. que a Agência Internacional de Energia Atômica, Órgão das Nações Unidas, julgou indispensável fundar em 1967 em Viena, onde tem sede, um centro Internacional de Informações Nucleares. Os dados obtidos em todos os centros de pesquișa que com ela mantêm ligações, e as informações científicas publicadas em todo o mundo são, anualmente, jogàdas nas memóriàs eletrônicas dos computadores, a fim de servir aos cientistas è pesquisadores de todo o mundo que necessitam, urgentemente, poupar tempo e dinheira na busca de soluções, as quais, muitas vêzes, podem ser fàcilmente conseguidas com a utilização de dados a que êles, de outra maneira, não teriam acesso.

$\mathrm{Na}$ medida em que caminharmos no aprimoramento de nossos conhecimentos científicos, mais próximos estaremos dêsses processos que só a sofisticação tecnológica permite resolver de maneira rápida e operacional. Parece-me indispensável, por isso, a utilização dos meios mais modestos, porém não menos eficazes, que podemos ter ao nosso alcance, pois isto faz parte do planejamento indispensável ao trabalho do futuro. A solução ou as soluções que a Documentação pode nos fornecer já têm sido úteis em uma série de setores da Administração. O Supremo Tribunal Federal, por exemplo, que darante muito tempo padeceu do problema de acúmulo de serviço, em virtude das falhas de nossa processualística, deu um passo definitivo em favor de sua emancipação, na hora em que, pela uso racionalizado da súmula jurisprudeneial, pôde simplificar e acelerar os seus julgamentos, valendo-se da Documentação.

Não há por que não empregar também êsses instrumentos, no desejo de modernizar a Administração Federal. Foi partindo dêsse pressuposto, foi objetivando a diretriz de uma Reforma que não pode mais ser postergada, que a alta administração do DASP se mobilizou para tornar a Documentação ùm fator precioso dêsse 


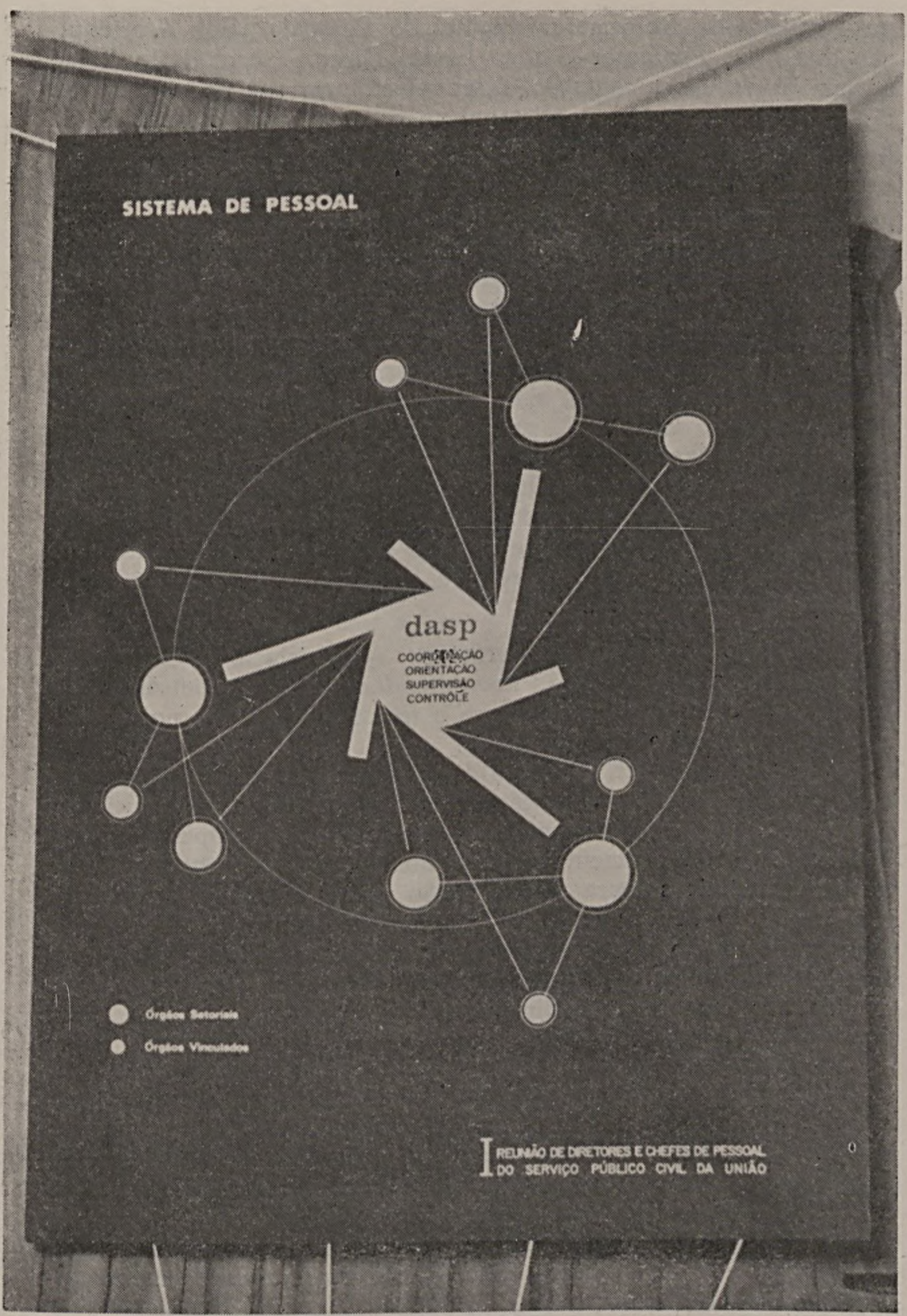


pré-requisito da Reforma no âmbitc do Pessoal. Sob a orientação direta do Professor Glauco Lessa, Diretor-Geral desta Casa, - Serviço de Documentação desenvolveu esforços na sentido de dotar a Administração de Pessoal no Serviço Público Federal, de um instrumento que, a seu ver, torna viável o uso racional dos Principios e Normas que regem o Pessoal Civil da União.

Penso que o Govêrno já demonstrou de maneira eloqüente que a descentralização administrativa, através de sucessivas delegações de competência, constitui preocupação fundamental de seu Programa. Tanto que, com êsse objetivo, inúmeros Atos têm sido baixados. É preciso, no entanto, orientar as autoridades que doravante passarão a decidir os assuntos, no tocante à execução da Política do Pessoal. Daí a oportunidade dessa nova filosofia de comportamento do DASP, procurando fazer chegar até às autoridades delegadas, ou aos órgãos setoriais de Pessoal que as assessorarão, a Legislação e a Orientação mais atualizada em matéria de Administração de Pesscal. Isto, certamente, os habilitarão a decidir com acêrto, dentro de normas consentâneas com a orien tação normativa do Poder Executivo, evitando-se os procedimentos discrepantes a que já aludi.

A edição do Boletim «DIRETRIZES》 - Legislação e Orientação Administrativa - constitui, no entender da Administração do DASP, um elemento decisivo para a racionalização das normas de Pessoal no Serviço Público Civil.

No meu entender, a edição de «DIRETREZES» é uma lição prática, de como a Documentação pode e deve ajudar a solucionar problemas. Já não se trata mais de colecionar textos, apenas. Mais do que isto, a Documentação e a informática constituem instrumentos dinâmicos para a aplicação dessa vasta e complexa legislação. O seu objetivo é, bàsicamente, informar, difundir e instruir, tornando acessiveis os preceitos muitas vêzes difíceis de serem identificados para aplicação casuística. Por isso mesmo são atividades eminentemente dinâmicas.

É tradicional afirmar-se que tanto a Documentação quanto a Informática constituem atividades-meio, eis que destinadas a servir de instrumentos à realização das atividades-fim de qualquer instituição. Dentro dessa nova planificação operacional do DASP, entretanto, ambas devem se transformar em autênticas atividades-fim, já que participarão, efetivamente, do sistema de pesşoal e a elas caberá a relevante missão de entrosar os órgãos que integram. E isto será feito, dando-lhes unidade imprescindivel ao seu bom êxito.

A realização dessa significativa tarefa exige a aplicação das mais aprimoradas técnicas e - acima de tudo - demanda ima ginação criadora, necessárias à dinamização das respectivas atividades. Essa missão extraordinária, em sua fase inicial, está a cargo de pequena e qualificada equipe, a que tenho a honra e o 
prazer de supervisionar. Aproveito por isso o ensejo para agradecer, de público, a dedicação e o espírito de sacrifício dos funcionários do próprio Serviço de Documentação e de outros setores do DASP que contribuiram, decisivamente, para os resultados ora apresentados e que se consubstanciam no exemplar de «DIRETRIZES» que os senhores receberam.

Agradeço também e de maneira muito especial, a quantos, com inexcediveis boa-vontade e atenção, ouviram esta fundamentação do que acreditamos ser a utilidade de nosso trabalho, cujo objetivo é levar-lhes uma parcela da nova dinâmica do DASP, que se inaugura de maneira tão auspiciosa nesta Reunião e que é fruto, em última análise, do espírito de equipe que aqui existe, sob a esclarecida direção do Professor Glauco Lessa de Abreu e Silva. 